\title{
The Social Coping Experiences of a Female Child with Arthrogryposis Multitplex Congenita Shared by her Parents
}

\author{
Mohaned Abed \\ King Abdulaziz University \\ Jeddah, Saudi Arabia \\ Email: mabed [AT] kau.edu.sa
}

\begin{abstract}
Arthrogryposis Multiplex Congenita, commonly referred to as AMC, is a disorder recognised by multiple contractures of the joints. The symptoms associated with the disorder span across various levels of severity. Regardless of the physical problems, however, intelligence remains undisturbed.
\end{abstract}

The aim of this paper is centred on investigating the social coping experiences of a child living with this condition, adopting a qualitative approach to the research. A case study design was adopted for the research, with the theoretical framework applied known as Phenomenology. One sample was used for the data collection, notably a child diagnosed with Arthrogryposis, with her coping experiences shared by her parents. When examining the data, thematic analysis was applied.

This study has significance in the fact it seeks to develop an understanding of children living with this condition, as well as for the disabled child population as a whole. The key issues seen to arise from this study include the role of social relationships, the role of the parent in socialisation, and the perceptions of others concerning AMC.

Keywords--- Social Coping Experiences, Arthrogryposis Multitplex Congenita, children with special needs

\section{INTRODUCTION}

Arthrogryposis Multiplex Congenita (AMC) is a descriptive term, which may be inferred to mean multiple curved joined. The incidence of AMC varies, possibly owing to the fact that eh term could be applied in the case of all individuals with multiple curved joints $(1: 3,000)$ or, on the other hand, only to those with no other potential diagnoses following in-depth examination (Fixsen, 2010). At least 150 different diagnoses were taken by Hall (1998), a geneticist, during which a baby was born with multiple curved joint deformities but quoted an incidence of classical AMC (amyoplasia congenita) of 1 in 10,000 live births.

As a term, AMC is not known by most people, with usually only those living with or having other experience of the condition familiar with this rare ailment. As has been stated by Shrout (1994), in the case of AMC, the individual's limbs are fixed in a particular position, with some or all of the joints involved, meaning that the limbs could be turned inwards, making their functionality and movement problematic. As has been highlighted by O'Flaherty (2001), AMC was initially recognised as a disease; subsequently, however, it became classified as a syndrome impacting babies' neuro-muscular systems throughout the pre-natal development phases. Also from the perspective of O'Flaherty's (2001), it is believed that AMC should be recognised as a syndrome and not as a disease. With this noted, it is stated that AMC 'is a condition often poorly understood in terms of its cause' (Fixsen, 2010, p. 183).

In terms of its prevalence, AMC is known to occur in 1 in 3,000 live births. In order to ensure accurate diagnosis, however, this should be carried out by an individual familiar with the condition, as highlighted by various scholars (Sells, Jaffe \& Hill, 1996). As noted by Sells, Jaffe \& Hill (1996), the most prevalent form of AMC is Amyoplasia. It should be noted that this condition affects not only the individual diagnosed but also their family and the surrounding community, which can be explained when considering the grades of severity of the individuals affected by this condition. In the view of Fixsen (2010), for those living with Arthrogryposis, the condition could be a taxing one, which applies to all individuals responsible for the care of the patient. This suggests that there are a number of challenges associated with not only living with the condition but also caring for the person diagnosed. Moreover, being a part of a non-disabled community could also induce a number of challenges and obstacles, particularly in aiding the non-disabled community to understand how the condition can be understood and managed. One of the key challenges is ensuring social interactions and being amongst non-disabled groups in describing this rate condition, especially during adolescence. 
A study centred on long-term AMC was carried out by Fassier et al. (2009); sadly, however, only the years from birth until skeletal maturity were covered. Importantly, the majority of literature available in the field appears to be paediatric and medically-centred, meaning the effects of day-to-day living with AMC have been disregarded or otherwise not considered. A book was written on AMC by Staheli et al. (1998), which considers a wealth of paediatric aspects of the condition, and is considered a valuable source of present knowledge but has no information or makes no discussion as to AMC in adulthood. The long-term effects of ACM, in line with adult issues, including employment, for example, could have been included in a final chapter, which would have positioned the book as providing a valuable ending. Information and literature pertaining to AMC in adult life remains absent, which provides some justification as to why those providing services to adults with AMC are not well informed or knowledgeable in regard to the condition.

In this research, the literature examined is dated owing to the fact that there is a lack of recent literature available on AMC.

It is essential to note that the child's parents, in the context of AMC, might choose to isolate themselves as a result of the perspectives adopted by people in their community towards people with AMC. As has been noted by Thomas (1982), attitude is defined as the views people hold, with Shrout (1994) emphasising that some parents choose to keep their (disabled) children from venturing into the outside world in an effort to safeguard them from harm-both physical and emotional. Such an approach could be a factor in how the child with AMC develops.

\subsection{Parental Roles}

A child's development is significantly impacted by their parents' role, with parents recognised by Palmer (1993) as 'providers of direct physical care', in addition to supporters and comforters during periods of illness (p. 187). As noted by Read (2000), mothers often experience problems in venturing outside with their disabled child, with a number of challenges facing carers. As has been highlighted by Oliver \& Sapey (2006), aiding in the practical elements of raising a child with a disabling condition is much more fundamental than the emotional responses to the disability of the child ( $p$. 96). Furthermore, the assumption is made that, by this point, parents will have come to learn all about the physical requirement(s) of their children, at which point their social needs and the importance of such are paramount. Throughout this period of children, the guidance of parents is essential, with the parents of those with AMC needing to encourage social relationships with others of the same age. AMC children's parents adopt a key role in the creation and building of the self-concept, with parental influence inducing either positive or negative reactions. It is common for AMC children' parents to be over-protective of their children.

As highlighted earlier on, non-disabled children might not be aware that those with AMC could be injured owing to the lack of reflexes, which provides some degree of rationale behind parents' overprotectiveness. In this vein, it is recognised by Luterman (1987) that, by being overprotective, a deaf child's parents could neglect to consider that, underneath the disability, there is an individual with needs and wants to be fulfilled. The concession made by Luterman (1987) is that parents of children with AMC could become overprotective, with the child's social life suffering as a consequence.

\subsection{Public Perception}

In the domain of AMC, public perception is another critical consideration, which has the potential to hinder the social life of the individual in question. Owing to the syndrome's overall nature, the person with AMC could be found to have hands in flexion, meaning in a fixed position, bent either inwards or outwards, which could cause questions to be asked relating to the reason behind this or what happened to cause this. Such questions suggest a curiosity concerning the condition, but insensitive questions could result in emotional harm inflicted upon the affected individual.

The point is argued by Morgan (1987) that those with disabilities are recognised as 'different' in the community (p. 15). Whist non-disabled members of society regard children with AMC as 'different', it could be difficult for the affected children to socialise, meaning they face the risk of social exclusion (Casas, 2007). When this is clear, it could be that children with AMC are viewed as not being good enough to interact with others in a social sphere (p. 463). For example, it is stated by Diamond \& Huang (2005) that ideas held by children in regard to disabled people are associated with their parents' beliefs concerning people with disabilities ' (p. 40). Accordingly, non-disabled children's parents could be influential in teaching negative stereotypes or positive, healthy virtues regarding those with disabilities. Unquestionably, however, society is not as negative regarding disabilities as it used to be; however, it remains that there are still negative views pertaining to disability. Potentially owing to the ignoring of some, members of the non-disabled community also associate physical problems with mental problems, despite the fact that those suffering with AMC are not affected on an intellectual basis. 


\subsection{Aim of Research}

In consideration to the condition's nature, people living with Arthrogryposis will be seen to be affected by varying degrees of severity, with the assumption therefore drawn that the social experiences of patients will differ from one to the next. With this in mind, this research seeks to investigate the social coping experiences of a child with AMC with the objective to develop greater understanding of and insight into Arthrogryposis in Saudi Arabia.

This research will be valuable for those affected by and diagnosed with AMC, and will provide contributions in terms of developing understanding and social support for the individual with Arthrogryposis, as well as for the disabled community as a population.

The significance of the study can be seen by considering the following:

1. It will provide an overview of Arthrogryposis for those who are unaware of this condition.

2. It will provide more in-depth insight regarding those living with the condition in Saudi Arabia in regard to how they can be affected at a social level.

\section{METHOD}

This research has been carried out through the adoption of a qualitative study approach. As has been explained by Banister et al. (1994), qualitative research seeks to provide understanding into underlying issues with the objective to identify the meaning of such issues under examination. In this regard, it is stated by Travers (2001) that learning about people is the same as learning about the language used by people. Developing insight into how people use language is examined in an effort to develop insight into what it means to be human, and, in the same regard, the human condition.

\subsection{Research Design}

This research adopts a case study design, throughout which, a specific programme, individual or event is examined indepth for a specified period of time (Leedy \& Ormrod, 2001, p. 149). The case study objective is to complete an in-depth examination, whereby a person is chosen by the research for more intense study than that warranted by, for example, a focus group approach. In mind of this research's purpose, emphasis is placed on the experiences of a child with Arthrogryposis. Accordingly, a case study approach is recognised as being well aligned with the objectives of the study. The data gathered in the application of this approach is invaluable owing to the view that such data will provide accurate insight into the social experiences of a child with this condition.

It is noted by Goodwin (1995) that the case study method can prove useful not only for individual cases but also when examining groups. The subject of this study is, as discussed earlier on, an adolescent with AMC. Accordingly, the children involved will be required to disclose various aspects of her social interaction experiences with non-disabled children.

In regard to the case study method, Yin (2003) also stated that, through the use of this approach, the subject will reveal to the researcher the true situation of his or her life. Moreover, the case study approach facilitates the researcher in developing a more wide-ranging understanding of the phenomenon under examination. In the view of Vadum \& Rankin (1998), case studies may prove valuable in gaining understanding of rare conditions, especially in specific regard to adolescents with Arthrogryposis, as in this situation (p. 1).

As noted by Coolican (2004), the case study approach has the potential to go against that which is taught through theory. In other words, a case study could provide evidence to contrast the presuppositions made by theory. Accordingly, in this case, the adolescent under investigation, who has been diagnosed with AMC, could provide insight into her situation that could ultimately go against the theory of social coping. Alternatively, however, the case study approach also has the potential to provide support of a theory, as recognised by scholars Shaughnessy, Zechmeister \& Zechmeister (2011). In this vein, the case study would require further examination in an effort to ensure the study findings are valid and generalisable (Shaughnessy, Zechmeister \& Zechmeister, 2011). As such, this could provide an avenue for further exploration by another research, who could be set on challenging the present study in an effort to either prove or disprove the psychology assumption made in regard to social coping. 


\subsection{Data Collection}

The data collection method, in the context of this research, comprises one sample, namely a child diagnosed with Arthrogryposis called Lena. This individual was recruited for involvement in the study from a centre for the physically disabled located in Jeddah, Saudi Arabia. The individual female lives with her parents and two sisters, and is significantly affected by the disorder, experiencing problems in the use of her hands owing to the fact they are curved inwards. Moreover, she also experiences problems in walking, and has to walk learning forward, her age was 3 . And she was the only one accepted by her parents to participate out of two cases found in Jeddah city due to the rare of the condition.

Interviews were carried out with the parents of the participant, notably at her home. Prior to scheduling the date and time for the interview, a good relationship was first established not only with the subject but also with her parents. Importantly, owing to age of the child, the parents were required to give consent for her to participate in the study.

In terms of duration, the interview was on-going for approximately 45-60 minutes. Open-ended questions were posed in an effort to satisfy the research aim. Arabic was used, with the interviews recorded and subsequently transcribed.

\subsection{Data Analysis}

The research is qualitative in nature, meaning the data analysis for the research was carried out with the use of thematic analysis. In terms of definition, thematic analysis may be described as the identification of themes seen to emerge as fundamental to the phenomenon description (Fereday \& Muir-Cochrane, 2006, p. 3).

Owing to the fact that thematic analysis was applied for the study, the themes seen to have emerged were categorised in line with suitable headings and accordingly discussed.

\subsection{Ethical Statement}

The research subject has been provided with details concerning the study purpose, with a great deal of importance assigned to anonymity and the option for the subject to withdraw from involvement at any stage. Moreover, confidentiality was assigned fundamental importance, which is a point that was stressed prior to the interview beginning. Involvement in the study was voluntary and the subject's consent was secured.

\section{RESULT AND DISCUSSION}

The main objective of treating children with AMC is concerned with ensuring their development into confident adults with the mechanisms and tools to aid them in coping with and managing their disabilities. This can be seen echoed in the literature, which focuses on AMC throughout childhood and adolescence, but without consideration to AMC in adult life. Such views are highlighted in the 1999 work by Sneddon.

Following the completion of the interview, a number of themes were identified, which provide insight into how the individual in question, and her parents, experiences social interactions with those in their community.

\subsection{Social Relationships}

It has been found that those with whom the child has social relationships include her sisters, as shown below in the following extracts:

Researcher: 'Okay... Okay. Her friends—-with particular emphasis on your non-disabled friends... Does she has nondisabled friends...?'

Mum: 'No.'

Researcher: 'Her sisters are her only friends?' 
Mum: 'Yes.'

Researcher: 'Okay. So, do her sisters allow her to feel part of their social circle?'

Mum: 'Yes, to some extent'

Researcher: 'They do to some extent. So would you say she feels confident and part of the group?'

Mum: 'Yes...'

As can be seen from the statements made above, it is clear that Lena socialises only with her sisters and parents.

As has been noted by Takemoto, cited in Hans \& Patri (2003), her parents were afraid for her to be judged by others owing to her disability.

Mom: 'Her friends are her sisters.'

Dad: 'and they do not play with her all the time as they want to run about when playing... She just stays in her place.'

Mom: 'That makes us play with her.'

Researcher: 'What about other children?'

Mom: 'We do not like how other people and children look at her. Other children look at her abnormality, such as her hands, and the operation's marks on her knees.'

It was also noted that Lena at the beginning, did not go to private nursery for children with special needs because of the fear that she be imitate the behaviours of those at nursery as she is mentally better than they are.

\subsection{Parental Role in Socialisation}

As shown throughout the course of the interview with Lena' parents, her mother could be seen as having a significant impact on her socialisation when considering how overprotective she is of her daughter. This is understandable. Moreover, as Lena is seriously affected by her condition, she requires much help with carrying out tasks. As a result, Lena needs her mother's involvement in her day-to-day living.

From what was gathered throughout the course of the interview, I developed the sense that Lena's mother holds much concern for the safety of her daughter, particularly when she is not around. However, when Lena's father is home, she is well cared for. Importantly, it was found that Lena's mother does not want someone else to care for her daughter:

Mom: '... I'm used to doing these things for my child, but others are not. Now someone else needs to do it for her. I know better than anyone else how she needs to be handled; how to take her to the toilet, give her food... I know exactly what needs to be done.'

As can be seen from the above except, the daughter's needs are well recognised by her mother. It is clear that Lena's mother is aware of various considerations in regard to her daughter's daily needs. As is evident from the fact that Lena's mother does not want anyone else to care for her daughter, she is seen to have a number of pressing concerns for the safety of Lena. Lena's mother feels it is her responsibility to give Lena care throughout the course of her life, but it remains that this could impact the various social aspects of Lena's life, with Palmer (1993), for example, noting the words 'comforter' and 'supporter', which sum up how Lena's mother views her own role in her daughter's care (p. 187).

\subsection{Others' Perception about Arthrogryposis}

Owing to the rarity of the Arthrogryposis condition, which is seen to occur in 1 in every 3,000 live births, as mentioned earlier, it is a disability that is not commonly seen. Owing to the fact that all cases of Arthrogryposis are different, the experiences in socialising can differ from one child to the next. Depending on the degree of severity to which the child is affected, they could experience physical challenges in partaking in social activities. Moreover, non-disabled children might not be interested in socially interacting with the children with this condition, again owing to the fact that the 
condition is not well known and therefore is not well understood. It was stated by the father in this case study that some doctors are not even aware of the condition.

The below statement was made in regard to the lack of information regarding this condition:

Mom: 'It was through my own knowledge (and later further research) that I could educate non-disabled friends and other people about this condition. I hate how people think ... they pretend that she is normal so not looking at her or not asking me about her and her progress so not making me upset.'

Father: 'we do not want to impose the problems with our child onto others who were not keen to socialise with her.'

It can be seen by the above that Lena does not provide others with information pertaining to her disorder, with the parents also mentioning that, in a similar vein, people do not want to learn about it. The conclusion can be drawn that it may be that other people are not interested in learning, or otherwise that Lena chooses not to discuss her problems with those with whom she does not feel comfortable.

Something else of interest to be noted is the fact that the parents would choose to go home if Lena was ignored by nondisabled children. With this comment in mind, it is clear to see that there are a number of aspects influencing Lena's socialisation and interactions.

In specific consideration to Lena's case, the researcher suggests that Lena should be involved in community activities where there are non-disabled children present. By doing this, the non-disabled community could be educated about the condition, as well as the physical needs of Lena. It is the responsibility of the parents to ensure people are educated so as to facilitate social interactions.

Although it is understandable that Lena's parents hold concerns regarding how they are treated by others, it remains that all children, regardless of ability, need to develop their own identity and be able to socialise with others. As has been identified from the interviews with Lena's parents, Lena's mother is seen to be quite overprotective of her daughter, which might not be helpful when considering how Lena copes from a social perspective.

Life with AMC has been widely treated with positivity, with acceptance emphasised by many, with the view commonly adopted that always there is somebody worse then them and that their disability positions them as more determined and able to deal with environmental, personal and social obstacles. This is a finding in line with the work of Resende \& Neri (2009), who recognised that those with a congenital disability were found to demonstrate a greater degree of psychological adjustment, and further showed more positive perspectives of personal aging. A number of obstacles and concerns were identified surrounding the various problems in establishing funding so as to support access, living with disability and opportunities, in addition to low expectations and the necessity to make changes to lifestyles in order to satisfy work demands.

\section{CONCLUSION}

As has been discussed, AMC is a very rare condition, and as such, is not well known by many people. Throughout the course of this investigation, it became clear that Lena's condition is not well understood by the non-disabled community. There is the indication that, as mentioned, the condition lacks understanding amongst most people. However, it is imperative to be willing to educate others on the condition in order to facilitate awareness and the socialisation of Lena in non-disabled groups. Offering understanding could also help Lena to find acceptance of her condition.

This study makes a valuable contribution in the sense that it addresses the issues seen to affect an individual with AMC. Owing to the fact that this syndrome is different from one person to the next, there are varying degrees of severity and, correspondingly, with the parenting styles adopted. Importantly, however, it is paramount to bear in mind that the social life of the child will be impacted, even if to a minor extent.

By carrying out this research, it is hoped that insight is given in regard to Arthrogryposis and its psychological effects. This research sought to develop awareness concerning the overall complexities associated with this condition, specifically in the social domain in Saudi Arabia.

\section{ACKNOWLEDGEMENT}

This article was funded by the Deanship of Scientific Research (DSR), King Abdulaziz University, Jeddah. The authors therefore, acknowledge, with thanks, the DSR technical and financial support. 


\section{REFERENCES}

- Gullotta, T. P., Adams, G. R., Markstrom, C. A., \& Adams, G. R. (2000). The adolescent experience. San Diego, Calif: Academic Press.

- Anonymous (1996). The role of the pediatrician in prescribing therapy services for children with motor disabilities. American Academy of Pediatrics Committee on Children With Disabilities. Pediatrics. 98, 308-10.

- Banister, P. (1994). Qualitative methods in psychology: a research guide. Philadelphia, Open University Press.

- Berns, R. (2004). Child, family, school, community: socialization and support. Belmont, CA, Wadsworth/Thomson Learning.

- Casas, I. (2007). Social Exclusion and the Disabled: An Accessibility Approach. The Professional Geographer. 59, 463-477.

- Coolican, H. (2004). Research methods and statistics in psychology. London, Hodder \& Stoughton.

- Diamond, K. E., Huang, H. (2005). Infants \& Young Children. An Interdisciplinary Journal of Special Care Practices. 18, 1, 37-46.

- Fereday, J., Muir-Cochrane, E. (2006). Demonstrating Rigor Using Thematic Analysis: A Hybrid Approach of Inductive and Deductive Coding and Theme Development. International Institute for Qualitative Methodology. $5,1-11$.

- Fixsen, J. A. (2010). Athrogryposis multiplex congenital. In: Benson M, Fixsen J, Macnicol M, Parsch K, eds. Children's Orthopaedics and Fractures 3rd Edition. Springer. Chapter 20, 327-334.

- Staheli, L. T. (1998). Arthrogryposis: A text atlas. New York: Cambridge University Press.

- Goodwin, C. J. (1995). Research in psychology: methods and design. New York, J. Wiley.

- Ham, R., Alersea, P., \& Porter, D. (1998). Wheelchair users and postural seating: a clinical approach. London, Churchill Livingstone.

- Hans, A., \& Patri, A. (2003). Women, disability, and identity. New Delhi, Sage Publications.

- Healy, A., Smith, B., \& Keesee, P. D. (1989). Early services for children with special needs: Transactions for family support. Baltimore, Md: P.H. Brookes Pub. Co.

- Leedy, P. D., \& Ormrod, J. E. (2005). Practical research: Planning and design. Upper Saddle River, N.J: Prentice Hall.

- Luterman, D. (1987). Deafness in the family. Boston: College-Hill Press.

- Millard, D. M. (1984). Daily living with a handicapped child. London: Croom Helm.

- Morgan, S. R. (1987). Abuse and neglect of handicapped children. Boston: Little, Brown.

- Morris, J. (1993). Independent lives?: Community care and disabled people. Basingstoke: Macmillan.

- Mueller, W. (1994). Understanding today's youth culture. Wheaton, Ill: Tyndale.

- O'Flaherty, P. (January 01, 2001). Arthrogryposis multiplex congenita. Neonatal Network : Nn, 20, 4, 13-20.

- OLIVER, M., \& BARNES, C. (1998). Disabled people and social policy: from exclusion to inclusion. London, Longman.

- OLIVER, M., \& SAPEY, B. (2006). Social work with disabled people. Basingstoke, Hampshire, Palgrave Macmillan. 
- Palmer, S. J. (February 01, 1993). Care of sick children by parents: a meaningful role.Journal of Advanced Nursing, 18, 2, 185-191.

- Pinkard, T. P. (1994). Hegel's Phenomenology: The sociality of reason. Cambridge: Cambridge University Press.

- Prilleltensky, O. (2004). Motherhood and disability: Children and choices. Houndmills, Basingstoke, Hampshire: Palgrave Macmillan.

- $\quad$ Read, J. (2000). Disability, the family, and society: Listening to mothers. Buckingham: Open University Press.

- Seale, C. (2004). Qualitative research practice. London: SAGE.

- Seiffge-Krenke, I. (1995). Stress, coping, and relationships in adolescence. Mahwah, N.J: L. Erlbaum Associates.

- Sells, J. M., Jaffe, K. M., \& Hall, J. G. (January 01, 1996). Amyoplasia, the most common type of arthrogryposis: the potential for good outcome. Pediatrics, 97, 2, 225-31.

- Shaughnessy, J. J., Zechmeister, E. B., \& Zechmeister, J. S. (2011). Research methods in psychology. New York, NY: McGraw-Hill.

- Shrout, D. S. (1994). Understanding and accommodating physical disabilities: The manager's desk reference. Westport, Conn: Quorum Books.

- Silverman, D. (2011). Qualitative research: Issues of theory, method, and practice. Los Angeles: Sage.

- $\quad$ Snyder, C. R. (2001). Coping with stress: Effective people and processes. Oxford: Oxford University Press.

- Thomas, D. J. (1982). The experience of handicap. London: Methuen.

- $\quad$ Travers, M. (2001). Qualitative research through case studies. London: SAGE.

- $\quad$ Turner, J. C. (1991). Social influence. Pacific Grove, Calif: Brooks/Cole.

- Vadum, A. C., \& Rankin, N. O. (1998). Psychological research: Methods for discovery and validation. Boston, Mass: McGraw-Hill.

- Vandenberg, D. (1997). Phenomenology and educational discourse. Johannesburg: Heinemann.

- Vander, Z. J. W. (1988). The social experience: An introduction to sociology. New York: Random House.

- Wright, B. A. P. (1983). Physical disability, a psychosocial approach. New York: Harper \& Row.

- Yin, R. K. (2003). Case study research: Design and methods. Thousand Oaks, Calif: Sage Publications. 